\title{
Homolytic C-NO 2 Bond Cleavage in Diaminodinitroethylene Isomers - A DFT Treatment
}

\section{Lemi Türker}

Department of Chemistry, Middle East Technical University, Üniversiteler, Eskişehir Yolu No: 1, 06800 Çankaya/Ankara, Turkey; e-mail: lturker@gmail.com; lturker@metu.edu.tr

\begin{abstract}
Diaminodinitroethylene (DADNE) has three isomers including the well known geminal isomer, FOX-7. In the present study, the homolytic cleavage of one of the $\mathrm{C}-\mathrm{NO}_{2}$ bonds of these isomers has been considered within the constraints of density functional theory at the level of UB3LYP/6-311++G(d,p). Transition states for that type of bond rupture are obtained. Various quantum chemical properties of the parent compounds and the decomposed systems are obtained, compared and discussed. Also the activation energies are calculated. The transition state originating from cis DADNE and the one from the geminal DADNE are found to be the most and least stable ones, respectively among the all.
\end{abstract}

\section{Introduction}

Diaminodinitroethylene possesses three structural isomers. One of them, the geminal one, is well known FOX-7 [1]. The others are cis- and trans-isomers. FOX-7, 1,1diamino-2,2-dinitroethylene, is also known as DADNE or DADE. The FOI (Swedish Defense Research Agency) members synthesized it in 1998 [2, 3] and its explosive potential was thoroughly investigated [4-18]. Its synthesis was also achieved by the nitration of 4,6-dihydroxy-2-methylpyrimidine and followed by hydrolysis [19].

Received: May 25, 2020; Accepted: June 29, 2020

Keywords and phrases: DADNE, FOX-7, explosive, bond cleavage, activation energy, density functional.

Copyright (C) 2020 Lemi Türker. This is an open access article distributed under the Creative Commons Attribution License, which permits unrestricted use, distribution, and reproduction in any medium, provided the original work is properly cited. 


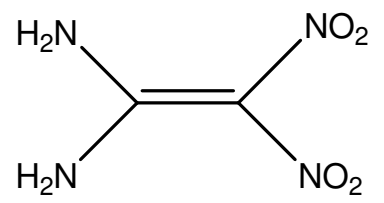

FOX-7

FOX-7 is a novel high-energy insensitive material having good thermal stability and low sensitivity. Albeit the fact that no structural resemblance exists among FOX-7, RDX and HMX they have the same $\mathrm{C} / \mathrm{H} / \mathrm{N} / \mathrm{O}$ ratio but FOX-7 is much less sensitive than RDX (in terms of impact, friction, and electrostatic discharge sensitivities [20]). It exhibits excellent application performance in the field of insensitive ammunitions (IM) and solid propellants.

FOX-7 shows abundant and surprising chemical reactivity although its molecular composition and structure is simple [21, 22]. It is due to the amino and nitro groups (push-pull groups) it has.

FOX-7 has many polymorphic forms. Of those, the $\alpha$-form reversibly turns into $\beta$-form by heat treatment $[23,24]$. However, at higher temperatures, $\beta$-polymorph undergoes an irreversible conversion to $\gamma$-phase which undergoes decomposition at 504 $\mathrm{K}$ [23]. Its decomposition pathway has been extensively investigated [25]. Also the effect of high pressure on the crystal structure of FOX-7 has been searched [26].

FOX-7 is an attractive ingredient. It also possesses the ability of increasing the burning rate in propellants, thus it is of interest for high performance propellants [1]. In order to obtain a reduced or minimum smoke producing composite propellant with inherent IM-properties many FOX-7 based propellant formulations have been studied [27].

Thermo chemical calculations have indicated that PBX's based on FOX-7 and energetic binders could serve as a replacement of Comp-B even at rather low solid loadings. A plastic bound explosive based on FOX-7 and an energetic binder have been prepared, [28].

On the other hand, the effects of nitration and epoxidation on ballistic properties of FOX-7 were also investigated within the restrictions of density functional theory (DFT) [29]. Also, some ground state properties of FOX-7 were calculated based on B3LYP/aug-cc-pVDZ predictions [30]. The other isomers of DADNE are not as famous as FOX-7. 
In order to achieve the direct optical ignition of an insensitive explosive, laser ignitibility of FOX-7 was investigated [31]. Recently, some novel derivatives of FOX-7 (geminal DADNE) and their properties as energetic materials have been reported [32, 33]. In the present study, homolytic $\mathrm{C}-\mathrm{NO}_{2}$ bond cleavage in DADNE isomers have been investigated within the constraints of density functional theory (DFT).

\section{Method of Calculation}

Structure optimizations leading to energy minima were initially achieved by using MM2 method which was followed by semi-empirical PM3 self-consistent fields molecular orbital (SCF MO) method [34, 35] at the restricted level [36, 37]. Subsequent optimizations were achieved at Hartree-Fock level by using various basis sets. Then, the optimizations were managed within the framework of density functional theory (DFT) using UB3LYP functional $[38,39]$ at the level of $6-311++G(d, p)$. The exchange term of B3LYP consists of hybrid Hartree-Fock and local spin density (LSD) exchange functions with Becke's gradient correlation to LSD exchange [39, 40]. The correlation term of B3LYP consists of the Vosko, Wilk, Nusair (VWN3) local correlation functional [41] and Lee, Yang, Parr (LYP) correlation correction functional [42]. The present vibrational analyses have been also done at the same level of calculations which had been performed for the optimizations. The total electronic energies (E) are corrected for the zero point vibrational energy (ZPE) to yield $\mathrm{E}_{\mathrm{c}}$ values. To minimize the basis set superposition error a rather high level basis set has been employed. The normal mode analysis for each structure yielded no imaginary frequencies for the $3 N-6$ vibrational degrees of freedom, where $N$ is the number of atoms in the system. This indicates that the structure of each molecule corresponds to at least a local minimum on the potential energy surface. Whereas in each case the IR spectrum shows a single imaginary frequency for the transition state structure. All these calculations were done by using the Spartan 06 package program [43].

\section{Results and Discussion}

Fox-7 is a push-pull type structure. The amino groups present in its structure are capable of donating electrons whereas the nitro groups act as acceptors. In the cis and trans DADNE isomers this effect might be in varying extents. Note that the presently considered DADNE isomers are all isoconjugate with some even alternant hydrocarbon 
anions [44-46]. This phenomenon is discussed in the literature that non-Kekulé alternant hydrocarbon isoconjugates may engender explosive materials when are subjected to suitable carbon-heteroatom perturbations [47]. Fox-7, the geminal DADNE isomer, is a non-Kekulé system having $\mathrm{n} *=7$ and $\stackrel{\circ}{n}=3$ positions whereas the $c i$ and trans isomers have $n^{*}=\stackrel{\circ}{n}=5$, thus they are isoconjugate with Kekulé systems (anions) (see refs. 44 and 45 for details of Kekulé and non-Kekulé systems). So, they are not expected, as a first approximation, to be explosive systems. However, they are worth investigating at the molecular level for mare scientific interest.

On the other hand, the initial step in thermal decomposition of nitro compounds is often the rupture of $\mathrm{C}-\mathrm{NO}_{2}$ or $\mathrm{N}-\mathrm{NO}_{2}$ bond [48]. The $\mathrm{C}-\mathrm{NH}_{2}$ bond is known to have a very high bond dissociation energy [49]. Therefore, in the present study only the homolytic $\mathrm{C}-\mathrm{NO}_{2}$ bond cleavage of DADNE isomers are considered. Figure 1 shows the optimized structures of DADNE isomers (parents) as well as the composite systems (daughters) obtained from them after the homolytic bond dissociation has occurred. The
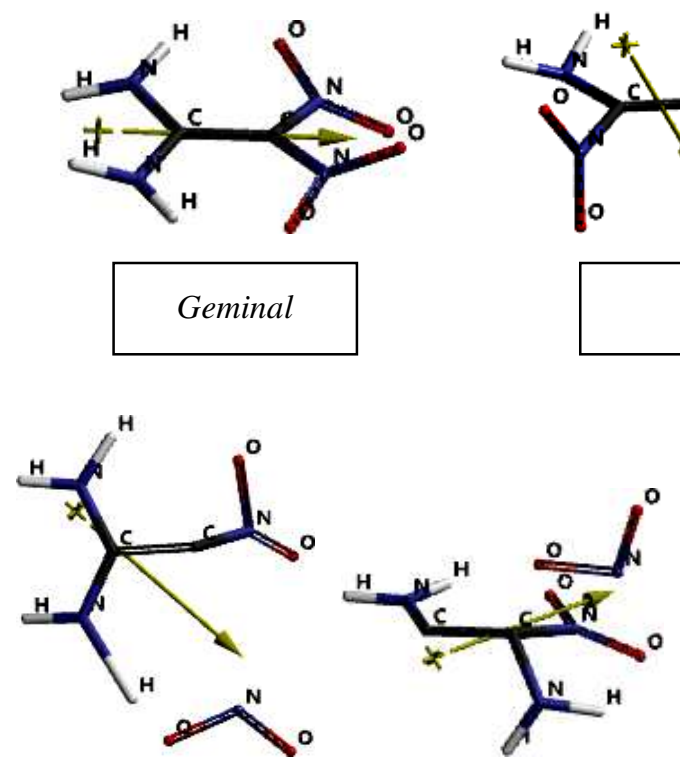

Geminal

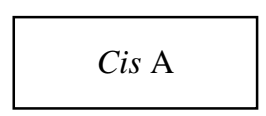

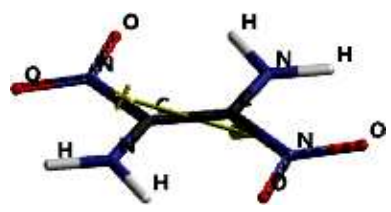

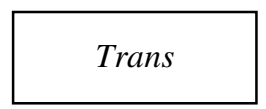

\section{Cis}
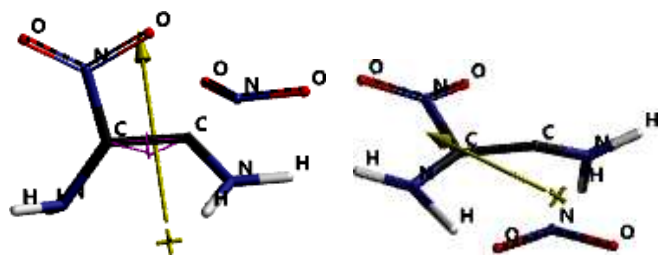

Cis $\mathrm{B}$

Trans

Figure 1. Optimized structures of the parents and the related transition states (daughters) considered. 
figure also shows the directions of the dipole moment vectors. Figure contains two transition state structures for the cis form. Of those, cis A transition structure originally related to cis isomer (parent structure) but the program while obtaining the transition state modifies it (nevertheless called cis A) and the transition state eventually obtained does not preserve the cis configuration (see Figure 1 for the amino groups). When the double bond of parent structure is initially locked in the cis configuration the program yields cis B transition state structure. Table 1 includes the numerical magnitudes of the dipole moment vectors. The orders of dipole moments for the parents and the daughters are geminal >cis $\mathrm{A}=$ cis $\mathrm{B}>$ trans and geminal >cis $\mathrm{B}>$ cis $\mathrm{A}>$ trans, respectively.

Table 1. Dipole moments of the systems of present concern.

\begin{tabular}{lcc}
\hline & Parents & Daughters \\
\hline Geminal & 8.53 & 7.62 \\
Cis A & 6.66 & 2.84 \\
Cis B & 6.66 & 6.77 \\
Trans & 0.00 & 2.53 \\
\hline
\end{tabular}

In debye units.

Figure 2 shows the calculated bond lengths of the transition states considered. In all the cases carbon-carbon bond lengths fall into the domain of 1.40-1.48 $\AA$. Whereas an experimental value reported that it is in a substituted and conjugated nitroethylene, 1-bromo-1-nitro-2-piperidino-(cyclohexylamino)-2-phenylethene (the $\mathrm{C}=\mathrm{C}$ bond length) is $1.399 \AA$ [50].

In Figure 2 in the geminal and trans cases, one of the N-H bonds is rather long than the other $\mathrm{N}-\mathrm{H}$ bond on the same nitrogen atom and they have some tendency to form hydrogen bonding with oxygen atom of the departing $\mathrm{NO}_{2}$ moiety. Then one of the $\mathrm{N}-\mathrm{O}$ bonds of the departing $\mathrm{NO}_{2}$ moiety elongates too. 

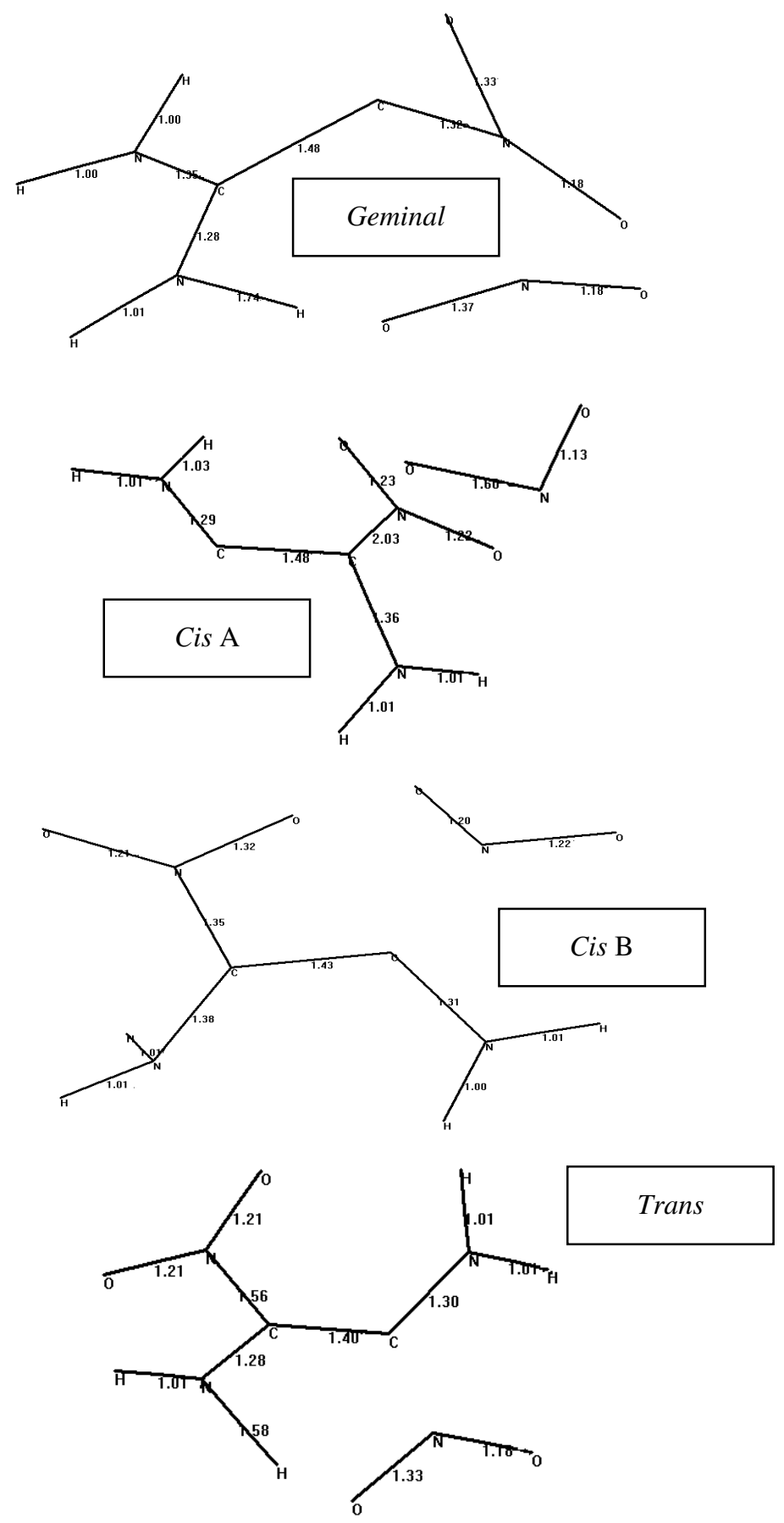

Figure 2. Calculated bond lengths (Á) of the transition states considered. 
Figure 3 shows the IR spectra of the transition state structures considered. In the
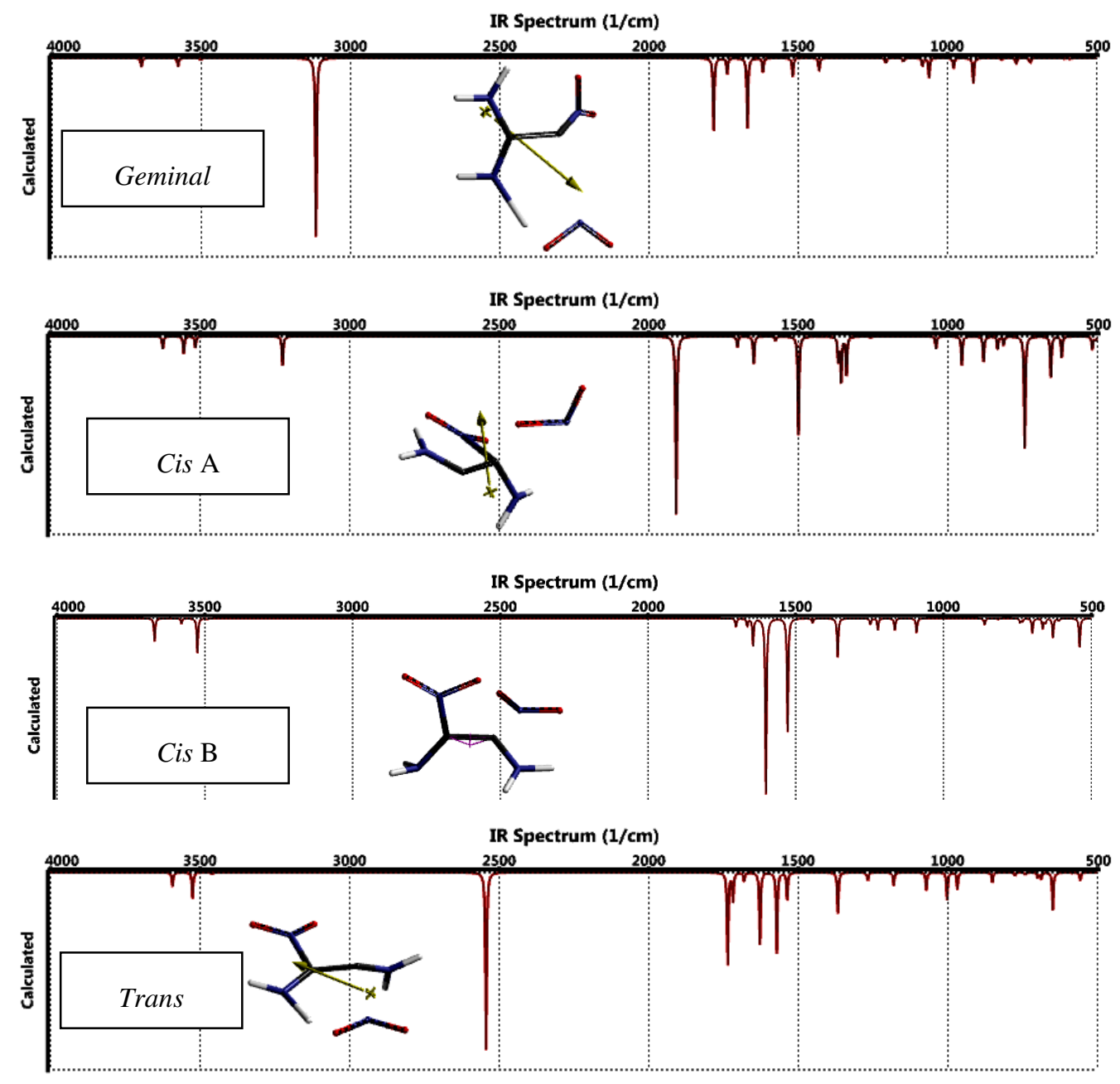

Figure 3. Calculated IR spectra of the transition states considered.

geminal case the weak peaks at 3701 and $3578 \mathrm{~cm}^{-1}$ stand for the asymmetric and symmetrical N-H stretchings belonging to the same $\mathrm{NH}_{2}$ group. The peaks at $3501 \mathrm{~cm}^{-1}$ (weak) and $3116 \mathrm{~cm}^{-1}$ (very strong) are N-H stretchings of the other amino group. The one at $3116 \mathrm{~cm}^{-1}$ belongs to the hydrogen which bonds to $\mathrm{NO}_{2}$ group departed. At 1783 $\mathrm{cm}^{-1} \mathrm{C}-\mathrm{NO}_{2}$ stretching occurs. At $1670 \mathrm{~cm}^{-1} \mathrm{NH}_{2}$ bendings and $\mathrm{C}-\mathrm{NH}_{2}$ stretching of the other amino group happen. 
In the case of cis A transition state structure, various N-H stretchings occur in between 3625 and $3224 \mathrm{~cm}^{-1}$. The N-O stretching of the departed $\mathrm{NO}_{2}$ moiety occurs at $1908 \mathrm{~cm}^{-1}$. The respective band for the other $\mathrm{NO}_{2}$ group is at $1500 \mathrm{~cm}^{-1}$. The spectrum of $c$ is $\mathrm{B}$ is different from cis $\mathrm{A}$. Note that although it is originally from cis parent and it is called cis A, it actually has trans form. The peaks for asymmetric and symmetrical N-H stretchings occur at $3670 \mathrm{~cm}^{-1}$ and $3525 \mathrm{~cm}^{-1}$, respectively. The peak at $1601 \mathrm{~cm}^{-1}$ stands for $\mathrm{N}-\mathrm{O}$ stretching overlapped with $\mathrm{N}-\mathrm{H}$ scissoring. The $\mathrm{C}=\mathrm{C}$ stretching coupled with various skeletal modes. As for the trans case, N-H stretchings occur $3592 \mathrm{~cm}^{-1}$ and $3525 \mathrm{~cm}^{-1}$ for different $\mathrm{NH}_{2}$ groups. At $2544 \mathrm{~cm}^{-1}$ another $\mathrm{N}-\mathrm{H}$ stretching (strong) happens. At about $1736 \mathrm{~cm}^{-1}$ various stretchings and bendings couple and overlap. The $\mathrm{N}-\mathrm{O}$ stretchings are observed at 1628 and $1572 \mathrm{~cm}^{-1}$.

Figure 4 shows the electrostatic potential (ESP) charges on the atoms of the transition state structures considered. Note that the ESP charges are obtained by the program based on a numerical method that generates charges that reproduce the electrostatic potential field from the entire wavefunction [43].

The figure indicates that the $\mathrm{NO}_{2}$ moiety in each case possesses some negative partial charge that is $-0.353,-0.063,0.063,-0.163$ esu for the cases originated from geminal, cis A, cis B and trans isomers, respectively. The charge on the carbon atom from where $\mathrm{NO}_{2}$ moiety is lost has the charge of $-0.396,-0.598$ and -0.420 esu, respectively for the isomers having the above mentioned sequence. Note that while a transition state progresses, some electron population can be conveyed from some other part of the molecule to the carbon atom at the terminus of the broken bond.
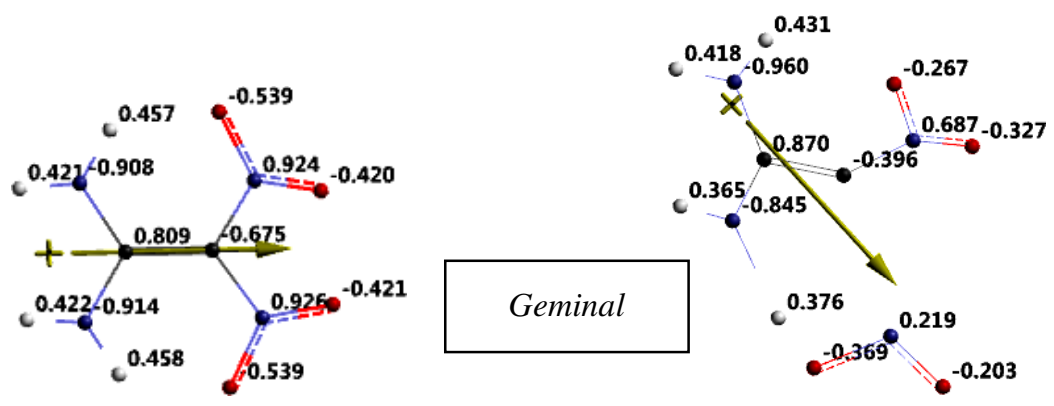

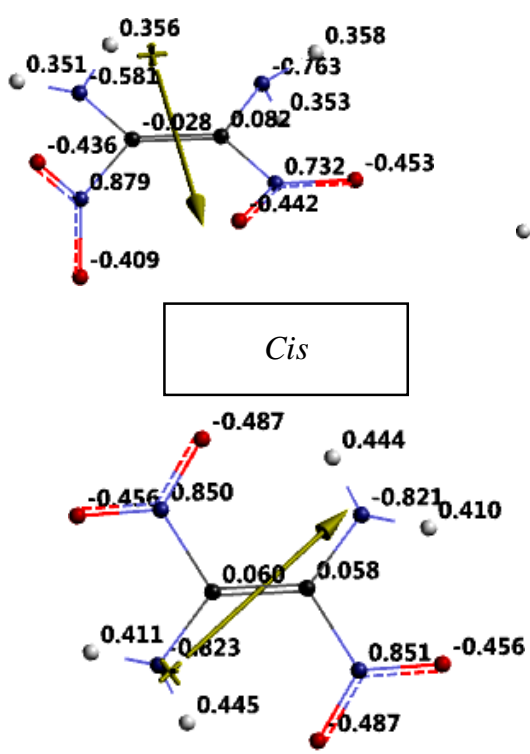

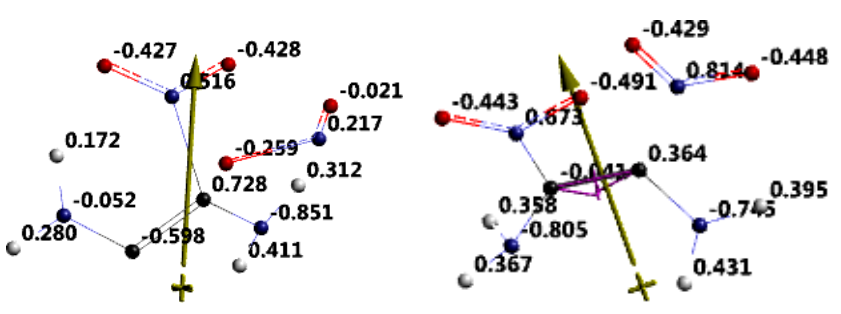

Cis $\mathrm{B}$
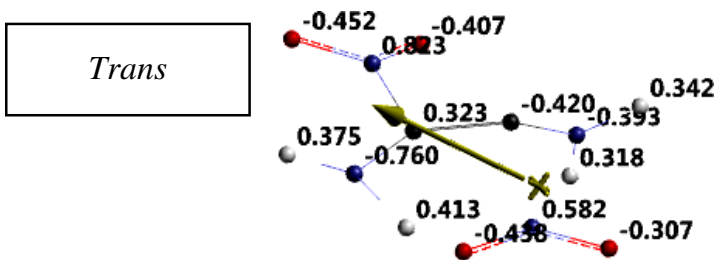

Figure 4. The ESP charges on atoms of the parent structures (left) and the transition states (right) considered.

Figure 5 shows the labeling of atoms of the transition state structures, a key to Table 2

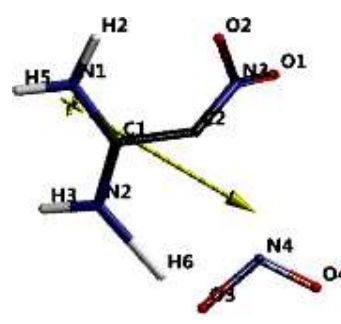

Geminal

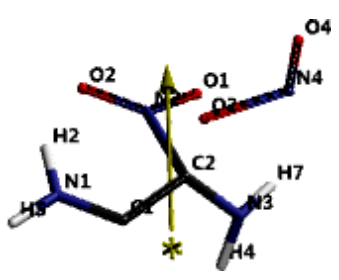

Cis A

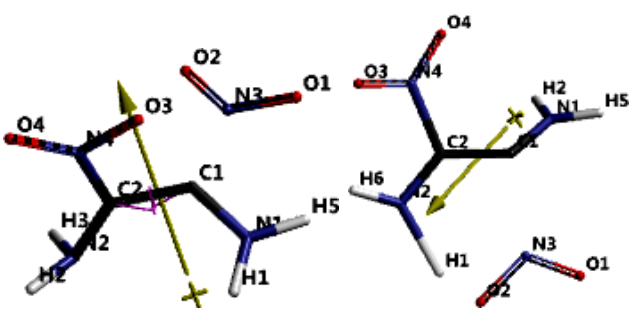

Cis B

\section{Trans}

Figure 5. Labeling of atoms of the transition state structures.

which lists Mulliken bond orders and bond lengths. A careful inspection of Figures 1-5 indicates that in the case of transition state geometry, called cis A form, it is actually trans (in terms of amino groups) in spite of the fact that the parent structure was cis. In other words while the cis structure approaches the transition state as $\mathrm{C}-\mathrm{NO}_{2}$ bond homolytically cleaves (whatever the mechanism is) the structure turns about $\mathrm{C} 1-\mathrm{C} 2$ bond and owes the trans geometry. The Mulliken analysis shows that $\mathrm{C} 1 \mathrm{C} 2$ bond is single in cis A structure but delocalized in the cases of cis $\mathrm{B}$ and trans forms. 
Table 2 also indicates that cis A transition state structure has delocalized C1-N1 and elongated $\mathrm{C} 2-\mathrm{N} 2$ bonds (C-NO 2 is elongated to $2.03 \AA$ ).

Table 2. Mulliken bond orders and bond lengths of the transition state structures.

\begin{tabular}{lcl}
\hline Bond & \multicolumn{2}{c}{ Geminal } \\
\hline C1 N1 & Bond order & Bond length $(\AA)$ \\
\hline C1 N2 & 1.205 & 1.3581 [single] \\
C1 C2 & 1.489 & 1.2841 [double] \\
N1 H2 & 0.877 & 1.4864 [deloc] \\
N1 H5 & 0.891 & 1.0087 [sing-H] \\
N2 H3 & 0.878 & 1.0072 [sing-H] \\
H6 O3 & 0.771 & 1.0018 [sing-H] \\
N3 O1 & 1.914 & 1.1878 [double] \\
N3 O2 & 1.165 & 1.3312 [single] \\
N3 C2 & 1.092 & 1.3252 [single] \\
O2 C2 & 0.838 & 1.7708 [single] \\
N4 O3 & 1.119 & 1.3738 [single] \\
N4 O4 & 2.019 & 1.1810 [double] \\
\hline
\end{tabular}

Cis A

Cis $\mathrm{B}$

\begin{tabular}{cclccl}
\hline Bond & Bond order & Bond length $(\AA)$ & Bond & Bond order & Bond length $(\AA)$ \\
\hline C1 C2 & 0.966 & 1.4803 [single] & N4 O3 & 1.314 & 1.3297 [deloc] \\
C1 N1 & 1.524 & 1.2949 [deloc] & N4 O4 & 1.818 & 1.2186 [double] \\
C1 H2 & 0.063 & 2.0571 [Hbond] & N4 C2 & 1.066 & 1.3525 [single] \\
C1 H4 & 0.058 & 2.5098 [Hbond] & C2 N2 & 1.267 & 1.3850 [deloc] \\
C2 N3 & 1.198 & 1.3691 [single] & C2 C1 & 1.357 & 1.4333 [deloc] \\
C2 N2 & 0.588 & 2.0398 [single] & N2 H2 & 0.915 & 1.0129 [sing-H] \\
C2 O3 & 1.555 & 1.3480 [deloc] & N2 H3 & 0.908 & 1.0154 [sing-H] \\
N1 H2 & 0.767 & 1.0327 [sing-H] & C1N1 & 1.411 & 1.3149 [deloc] \\
N1 H5 & 0.873 & 1.0134 [sing-H] & C1 N3 & 0.651 & 1.5551 [single] \\
H2 O2 & 0.128 & 1.8866 [Hbond] & N1 H1 & 0.867 & 1.0088 [sing-H] \\
N3 H4 & 0.884 & 1.0117 [sing-H] & N1 H5 & 0.863 & 1.0141 [sing-H] \\
N3 H7 & 0.887 & 1.0150 [sing-H] & H5 O1 & 0.059 & 2.1601 [Hbond] \\
N2 O1 & 1.822 & 1.2218 [double] & N3 O1 & 1.772 & 1.2219 [double] \\
N2 O2 & 1.738 & 1.2373 [double] & N3 O2 & 1.925 & 1.2088 [double] \\
N4 O3 & 0.614 & 1.6059 [single] & N4 O3 & 1.314 & 1.3297 [deloc] \\
N4 O4 & 2.309 & 1.1362 [triple] & & & \\
\cline { 1 - 3 } & & & &
\end{tabular}


Trans

\begin{tabular}{ccl}
\hline Bond & Bond order & Bond length $(\AA)$ \\
\hline C1 C2 & 1.494 & 1.4086 [deloc] \\
C1 N1 & 1.556 & 1.3018 [deloc] \\
C2 N2 & 1.651 & 1.2809 [deloc] \\
C2 N4 & 0.561 & 1.5691 [single] \\
N1 H2 & 0.851 & 1.0166 [sing-H] \\
N1 H5 & 0.871 & 1.0112 [sing-H] \\
N2 H1 & 0.109 & 1.5903 [Hbond] \\
N2 H6 & 0.845 & 1.0170 [sing-H] \\
H1 O2 & 0.719 & 1.0347 [sing-H] \\
H6 O3 & 0.067 & 2.2143 [Hbond] \\
N3 O1 & 2.1 & 1.1846 [double] \\
N3 O2 & 1.277 & 1.3367 [deloc] \\
N4 O3 & 1.852 & 1.2159 [double] \\
N4 O4 & 1.86 & 1.2166 [double] \\
\hline
\end{tabular}

Possible mechanistic routes to formation of the cis A transition state might be rationalized within the valence bond treatment as shown below where in path III electrons from the broken bond are shown in smaller size.
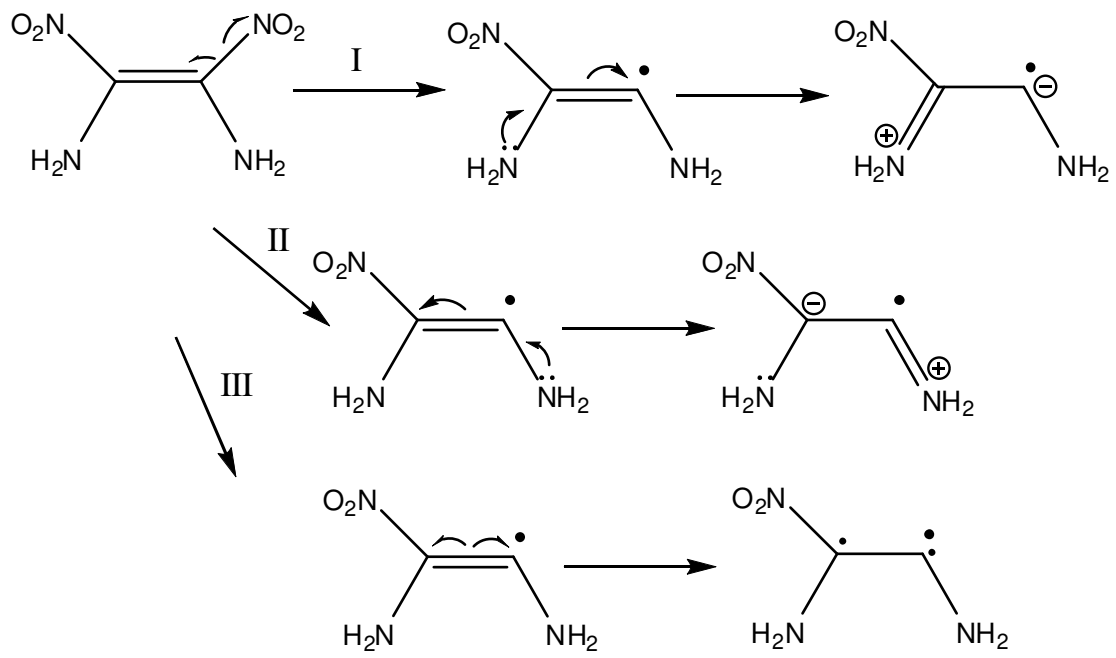

In each route, first vinylic type radical forms. In route I donation of electrons by the amino group, should form a radical anion but the electron pair of the anion and electron of the radical occupy different orbitals of the terminal carbon atom. Whereas in route II the electron pair and radical are on different carbons. Note that the anion formed in II is much better stabilized than the anion of route I because it is delocalized over a much 
larger space including the nitro group. Route III is less likely because it possesses three unpaired electrons. Note that electrons on the carbon atom of the reaction terminus occupy orthogonal orbitals, thus the initial vinylic radical does not gain extra stabilization by undergoing homolytic bond cleavage of the carbon-carbon double bond. Thus routes I and more likely route II result carbon-carbon single bond which allows rotation of the groups about it to access the trans orientation.

Table 3 shows the total electronic energy (E), zero point vibrational energy (ZPE) and the corrected total electronic energy $\left(\mathrm{E}_{\mathrm{c}}\right)$ of the present parent structures. The order of $\mathrm{E}_{\mathrm{C}}$ values is geminal < trans < cis. Note that the stability order is the reverse. These orders have to be dictated by the push-pull effects of the amino and nitro groups at different locations and different extents.

Table 3. Some energies of the parent structures.

\begin{tabular}{lccc}
\hline Structure & $\mathbf{E}$ & $\mathbf{Z P E}$ & $\mathbf{E}_{\mathbf{c}}$ \\
\hline Geminal & -1571382.63 & 240.699871 & -1571141.93 \\
Cis & -1571317.89 & 239.235684 & -1571078.65 \\
Trans & -1571363.24 & 238.058343 & -1571125.18 \\
\hline
\end{tabular}

Energies in $\mathrm{kJ} / \mathrm{mol}$.

Whereas Table 4 displays some similar data for the transition state structures. This time the stability order based on $\mathrm{E}_{\mathrm{c}}$ values is cis $\mathrm{B}>$ cis $\mathrm{A}>$ trans $>$ geminal. It is note worthy that stability order of the composite systems (daughters) is parallel to the respective order of the parent structures.

Table 4. Some energies of the transition states considered.

\begin{tabular}{lccc}
\hline Structure & $\mathbf{E}$ & $\mathbf{Z P E}$ & $\mathbf{E}_{\mathbf{c}}$ \\
\hline Geminal & -1571082.07 & 221.71 & -1570860.36 \\
Cis A & -1571189.37 & 226.70 & -1570962.67 \\
Cis B & -1571220.08 & 236.49 & -1570983.59 \\
Trans & -1571173.87 & 227.79 & -1570946.08 \\
\hline
\end{tabular}

Energies in $\mathrm{kJ} / \mathrm{mol}$. 
Figure 6 displays distribution of some of the molecular orbital energies of the transition
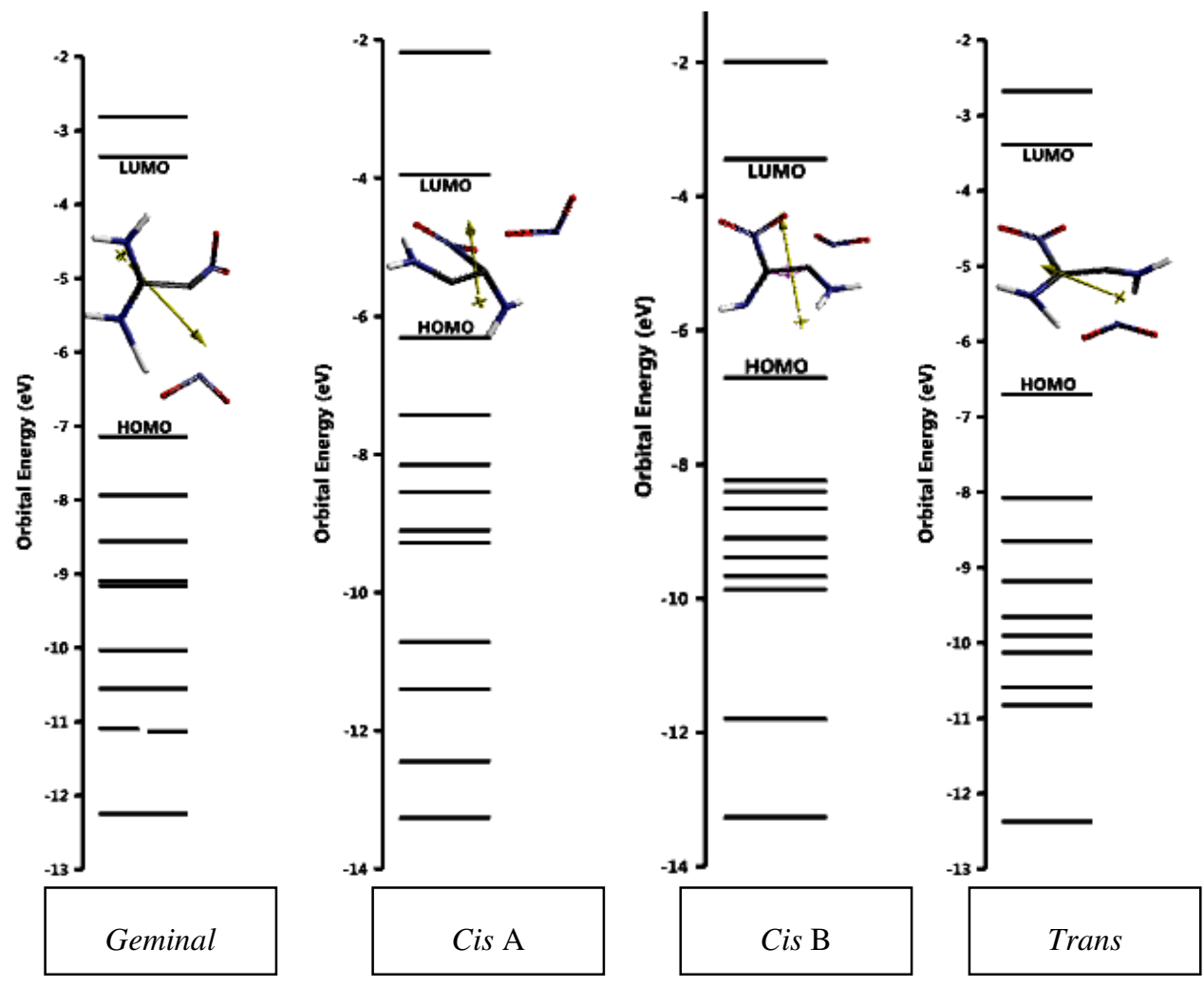

Figure 6. Some of the molecular orbital energies of the transition states considered.

states considered. Whereas Table 5 shows the HOMO, LUMO energies and the interfrontier molecular orbital energy gaps $(\Delta \varepsilon)$ of the parent and daughter systems.

The order of HOMO energies is geminal < cis < trans for the parents and geminal < cis $\mathrm{B}<$ trans $<$ cis $\mathrm{A}$ for the daughter systems. As for the LUMO energies the order is trans $<$ cis $<$ geminal for the parents and cis $\mathrm{A}<$ cis $\mathrm{B}<$ trans $<$ geminal for the daughters. Note that in the table the parents of cis A and cis B is the same. One more thing to be mentioned is that although cis $\mathrm{A}$ and trans daughters have trans orientation in terms of the $\mathrm{NH}_{2}$ groups they are different. 
Table 5. The HOMO, LUMO energies and $\Delta \varepsilon$ values of the structures of present concern.

\begin{tabular}{lccc}
\hline Structure & HOMO & LUMO & $\Delta \boldsymbol{\varepsilon}$ \\
\hline Geminal & -724.45 & -276.64 & 447.81 \\
& -689.64 & -324.10 & 365.54 \\
& & & \\
Cis A & -717.60 & -311.55 & 406.05 \\
& -608.38 & -381.38 & 227 \\
& & & \\
Cis B & -717.60 & -311.55 & 406.05 \\
& -646.84 & -332.34 & 314.5 \\
& & & \\
Trans & -632.59 & -381.93 & 250.66 \\
& -646.81 & -326.65 & 320.16
\end{tabular}

Energies in $\mathrm{kJ} / \mathrm{mol}$. In each row the first and second entries stand for the parent and daughter, respectively.

Figure 7 shows the HOMO and LUMO patterns of the transition states considered. As seen in the figure, in the case of geminal and trans transition structures the $\mathrm{NH}_{2}$ groups either contribute little or nil into the HOMO because the overall electron pull effect should have been decreased due to the absence of departing $\mathrm{NO}_{2}$ moiety. It is known that in general electron donors raise up the frontier molecular orbital energies and electron acceptors lower them. The overall electron pull-push effect is mainly dictated by the orientation of the groups and the conjugative possibilities. All these effects dictate the molecular orbital energies as well as shape the HOMO and LUMO patters.

Figure 8 shows the electrostatic potential maps of the transition states considered. In the figure the blue/bluish and red/reddish regions show the positive and negative potential regions, respectively. 

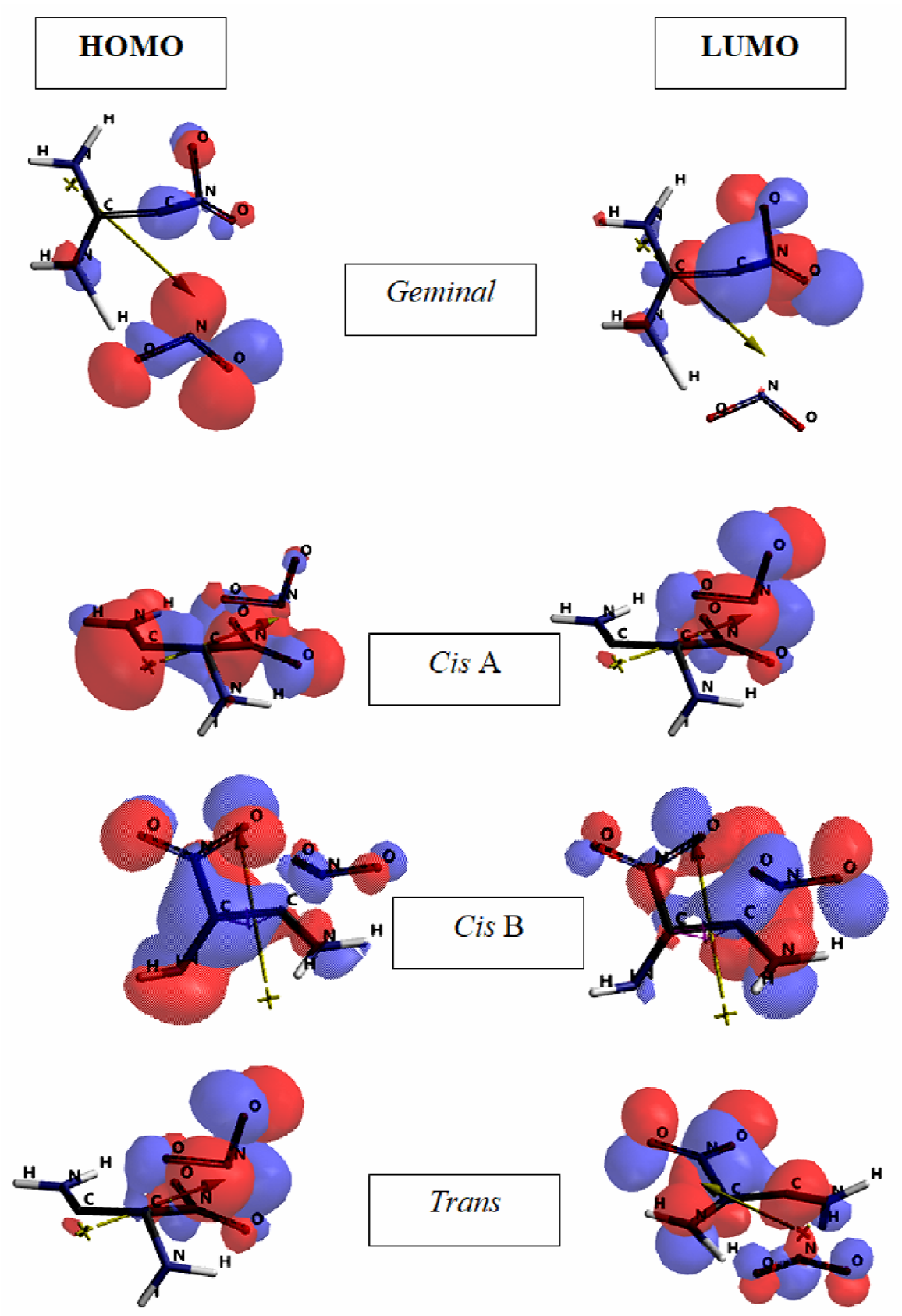

Figure 7. The HOMO and LUMO patterns of the transition states considered. 


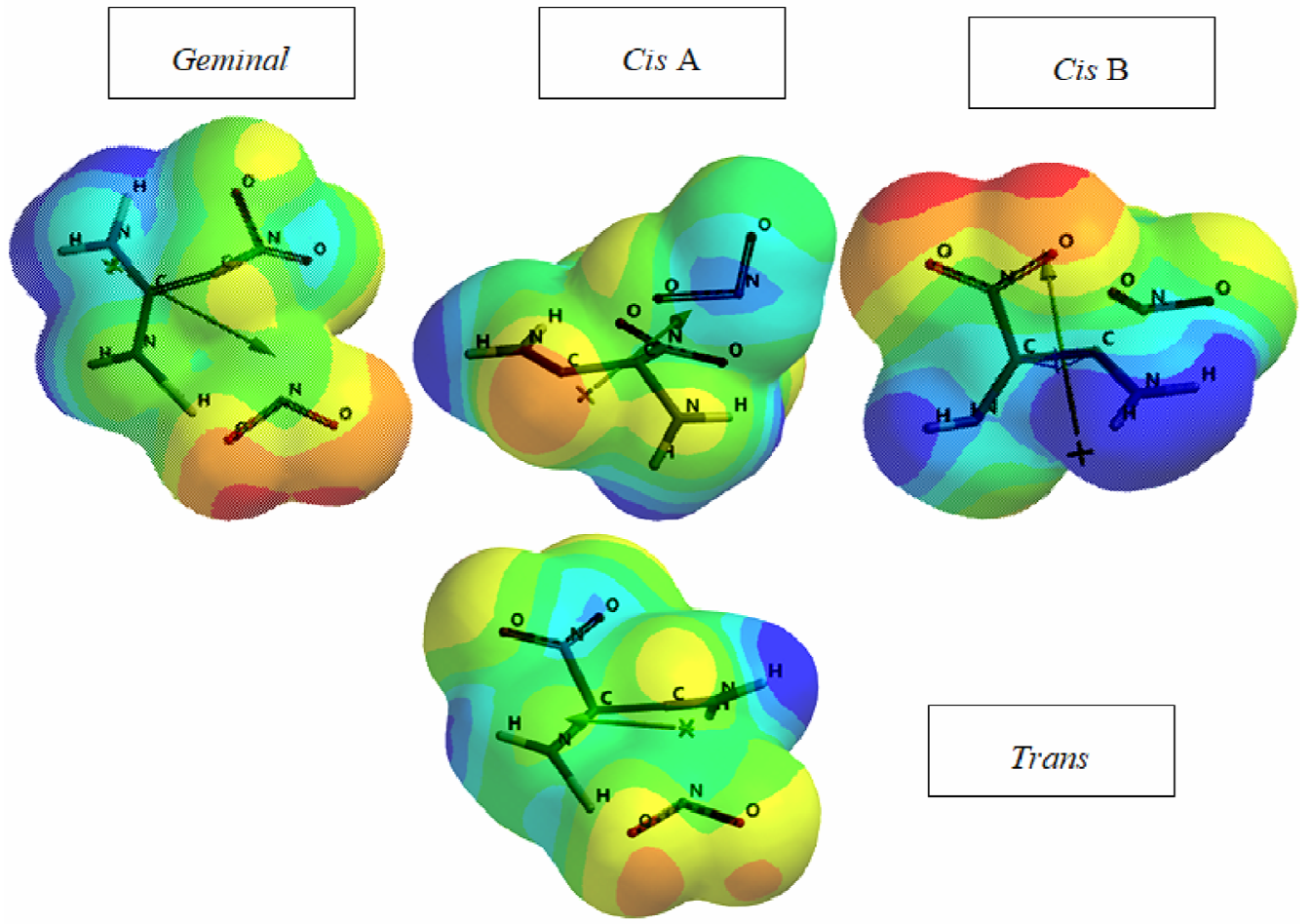

Figure 8. The electrostatic potential maps of the transition states considered.

Table 6 shows the activation energies of the homolytic dissociations considered. Whereas in Table 7 the $\Delta \stackrel{\mathbf{G}}{\mathbf{G}}^{\neq}$values of the considered transition states are displayed.

Table 6. Activation energies of the homolytic dissociations considered $\left(\mathrm{R}-\mathrm{NO}_{2} \longrightarrow \mathrm{R} \cdot+\cdot \mathrm{NO}_{2}\right)$.

\begin{tabular}{cccc}
\hline Geminal & Cis A & Cis B & Trans \\
\hline 281.5701 & 115.9843 & 95.06 & 179.1017 \\
\hline
\end{tabular}

Energies in $\mathrm{kJ} / \mathrm{mol}$. Based on electronic energies. See Tables 2 and 3 for $\mathrm{E}_{\mathrm{c}}$ values of the parent and the corresponding transition states, respectively. 
Table 7. The $\Delta \mathbf{\mathbf { G }}^{\neq}$values of the transition states considered.

\begin{tabular}{lccc}
\hline Structure & Parents $(\mathbf{G})$ & Daughters $(\stackrel{\mathbf{G}}{\mathbf{G}})$ & $\Delta \mathbf{G}^{\neq}$ \\
\hline Geminal & -1571243.438 & -1570968.288 & 275.1499 \\
Cis A & -1571181.711 & -1571068.992 & 112.7191 \\
Cis B & -1571181.711 & -1571086.011 & 95.7 \\
Trans & -1571226.695 & -1571050.501 & 176.1938 \\
\hline
\end{tabular}

Energies in $\mathrm{kJ} / \mathrm{mol}$.

According to the data present in Table $7, \Delta \mathbf{G}^{\neq}$values have the order of geminal > trans > cis $\mathrm{A}>$ cis $\mathrm{B}$. Namely, cis $\mathrm{B}$ transition state is less activation energy demanding transition state. Consequently, cis $\mathrm{B}>$ cis $\mathrm{A}>$ trans $>$ geminal order reflects the favorability of the homolytic dissociation of $\mathrm{C}-\mathrm{NO}_{2}$ bonds in the isomers considered. Namely, the homolytic cleavage of $\mathrm{C}-\mathrm{NO}_{2}$ bonds of the parents follow the order of cis $>$ trans $>$ geminal. Obviously, this order should be dictated by various configurational, conformational factors and charge and bond dipole effects in these isomeric structures.

\section{Conclusion}

Within the restrictions of density functional theory at the level of UB3LYP/6$311++\mathrm{G}(\mathrm{d}, \mathrm{p})$, the present investigation of the homolytic $\mathrm{C}-\mathrm{NO}_{2}$ bond cleavage of DADNE isomers has revealed that cis DADNE is the most, whereas the geminal one is the least susceptible parent structures. The transition state search for cis DADNE yields an unexpected configuration in which the amino groups occupy trans orientation. A plausible mechanisms has been suggested to explain the rotation about the carbon-carbon bond to generate trans configuration of the transition state structure. When the cis geometry of the parent compound is fixed, a transition state structure having the cis configuration is obtained which is electronically the most stable transition state whereas the geminal one (from FOX-7) has the least stable transition state (the most energetic). It requires the greatest activation energy among the isomers to undergo the homolytic $\mathrm{C}-\mathrm{NO}_{2}$ bond rupture. 


\section{References}

[1] J. P. Agrawal, High Energy Materials, Weinheim: Wiley-VCH, 2010. https://doi.org/10.1002/9783527628803

[2] P. Politzer and J. S. Murray, Energetic Materials, Part 1, Amsterdam: Elsevier, 2003.

[3] I. J. Lochert, FOX-7 - A New Insensitive Explosive, DSTO Aeronautical and Maritime Research Laboratory, 506 Lorimer St, Fishermans Bend, Victoria 3207 Australia, AR012-065, November 2001.

[4] N. V. Latypov, J. Bergman, A. Langlet, U. Wellmar and U. Bemm, Synthesis and reactions of 1,1-diamino-2,2-dinitroethylene, Tetrahedron 54 (1998), 11525-11536. https://doi.org/10.1016/S0040-4020(98)00673-5

[5] U. Bemm and H. Östmark, 1,1-Diamino-2,2-dinitroethylene: A novel energetic material with infinite layers in two dimensions, Acta Crystallogr. C 54 (1998), 1997-1999. https://doi.org/10.1107/S0108270198007987

[6] N. V. Latypov, A. Langlet and U. Wellmar, New chemical compound suitable for use as an explosive, intermediate and method for preparing the compound, Patent WO99/03818, 1999.

[7] H. Östmark, H. Bergman, U. Bemm, P. Goede, E. Holmgren, M. Johansson, A. Langlet, N. V. Latypov, A. Petterson, M. L. Petterson, N. Wingborg, C. Vörde, H. Stenmark, L. Karlsson and M. Hihkiö, 2,2-dinitro-ethene-1,1-diamine (FOX-7)-Properties, analysis and scale-up, $32^{\text {nd }}$ International Annual Conference of ICT on Energetic Materials - Ignition, Combustion and Detonation, Karlsruhe, Germany, 2001.

[8] H. Östmark, A. Langlet, H. Bergman, N. Wingborg, U. Wellmar and U. Bemm, FOX-7 A new explosive with low sensitivity and high performance, The $11^{\text {th }}$ International Detonation Symposium, Colorado, USA, 1998.

[9] H. Bergman, H. Ostmark, A. Pettersson, M. L. Petterson, U. Bemm and M. Hihkio, Some initial properties and thermal stability of FOX-7, Insensitive Munitions and Energetic Materials Symposium (NDIA), Tampa, Florida, USA, 1999.

[10] W. A. Trzciński and A. Belaada, 1,1-Diamino-2,2-dinitroethene (DADNE, FOX-7) Properties and formulations (a review), Cent. Eur. J. Energ. Mater. 13(2) (2016), 527544. https://doi.org/10.22211/cejem/65000

[11] B. Janzon, H. Bergman, C. Eldsater, C. Lamnevik and H. Ostmark, FOX-7 - A high performance, low vulnerability high explosive for warhead applications, $20^{\text {th }}$ Int. Symp. Ballistics, Orlando, Florida, USA, September 23-27, 2002. 
[12] Y. N. Matyushin, G. T. Afanas'ev, V. P. Lebedev, M. N. Mahov and V. I. Pepekin, TATB and FOX-7: Thermochemistry, performance, detonability, sensitivity, $34^{\text {th }}$ Int. Annu. Conf. ICT, Karlsruhe, Germany, June 24-27, 2003.

[13] A. J. Bellamy, N. V. Latypov and P. Goede, Studies on the nitration of new potential precursors for FOX-7, New Trends Res. Energ. Mater., Proc. Semin., $7^{\text {th }}$, Pardubice, Czech Republic, April 20-22, 2004.

[14] S. Cudziło, Z. Chyłek and R. Diduszko, Crystallization and characterization of 1,1diamino-2,2-dinitroethene (DADNE), 36 ${ }^{\text {th }}$ Int. Annu. Conf. ICT, Karlsruhe, Germany, June 28-July 1, 2005.

[15] W.A. Trzciński, S. Cudziło, Z. Chyłek and L. Szymańczyk, Investigation of sensitivity and detonation properties of FOX-7, $37^{\text {th }}$ Int. Annu. Conf. ICT, Karlsruhe, Germany, June 27-30, 2006.

[16] M. Anniyappan, M. B. Talawar, G. M. Gore, S. Venugopalan and B. R. Ganghe, Synthesis characterization and thermolysis of 1,1-diamino-2,2-dinitroethylene (FOX-7) and its salts, J. Hazard. Mater. B 137 (2006), 812-819.

https://doi.org/10.1016/j.jhazmat.2006.03.034

[17] W. A. Trzciński, S. Cudziło, Z. Chyłek and L. Szymańczyk, Detonation properties of 1,1diamino-2,2-dinitroethene (DADNE), J. Hazard. Mater. 157 (2008), 605-612. https://doi.org/10.1016/j.jhazmat.2008.01.026

[18] V. S. Mishra, S. R. Vadali, R. K. Garg, V. S. Joshi, R. D. Wasnik and S. Asthana, Studies on FOX-7 based melt cast high explosive formulations, Cent. Eur. J. Energ. Mater. (CEJEM) 10(4) (2013), 569-580.

[19] N. V. Latypov, M. Johansson, E. Holmgren, E. V. Sizova, V. V. Sizov and A. J. Bellamy, On the synthesis of 1,1-diamino-2,2-dinitroethene (FOX-7) by nitration of 4,6-dihydroxy2-methylpyrimidine, Org. Process Res. Dev. 11(1) (2007), 56-59.

https://doi.org/10.1021/op068010t

[20] T. M. Klapötke, Chemistry of High-Energy Materials, Berlin: De Gruyter, 2011. https://doi.org/10.1515/9783110227840

[21] Y. Zhang, Q. Sun, K. Xu, J. Song and F. Zhao, Review on the reactivity of 1,1- diamino2,2-dinitroethylene (FOX-7), Propellants Explos. Pyrotech. 41 (2016), 35-52. https://doi.org/10.1002/prep.201500065

[22] K. Baum, N.V. Nguyen, R. Gilardi, J. L. Flippen-Anderson and C. George, Nitration of 1,1-diamino-2,2-dinitroethylenes, J. Org. Chem. 57 (1992), 3026-3030.

https://doi.org/10.1021/jo00037a015 
[23] J. Evers, T. M. Klapötke, F. Mayer, G. Oehlinger, J. Welch, $\alpha$ - and $\gamma$-FOX-7 polymorphs of a high energy density material, studied by X-ray single crystal and powder investigations in the temperature range from 200 to $423 \mathrm{~K}$, Inorg. Chem. 45 (2006), 4996-5007. https://doi.org/10.1021/ic052150m

[24] M. J. Crawford, J. Evers, M. Göbel, T. M. Klapötke, P. Mayer, G. Oehlinger and J. M. Welch, $\gamma$-FOX-7: Structure of a high energy density material immediately, prior to decomposition, Propellants Explos. Pyrotech. 32 (2007), 478-495.

https://doi.org/10.1002/prep.200700240

[25] A. Gindulytè, L. Massa, L. Huang and J. Karle, Proposed mechanism of 1,1-diaminodinitroethylene decomposition: a density functional theory study, J. Phys. Chem. 103 (1999), 11045-11051. https://doi.org/10.1021/jp991794a

[26] Z. A. Dreger, A. I. Stash, Z. G. Yu, Y. S. Chen, Y. Tao and Y. M. Gupta, High-pressure crystal structures of an insensitive energetic crystal: 1,1-diamino-2,2-dinitroethene, $J$. Phys. Chem. C 120 (2) (2016), 1218-1224. https://doi.org/10.1021/acs.jpcc.5b10644

[27] H. Lips and K. Menke, FOX-7/GAP rocket propellants for a shoulder launched projectile, $27^{\text {th }}$ International Symposium on Ballistics, Freiburg, Germany, April 22-26, 2013.

[28] S. Karlsson, H. Östmark, C. Eldsäter, T. Carlsson, H. Bergman, S. Wallin and A. Pettersson, Detonation and sensitivity properties of FOX-7 and formulations containing FOX-7, FOI, Swedish Defence Research Agency, Grindsjöns Research Center, SE-147 25, Tumba, Sweden, 2002.

[29] L. Türker and S. Varış, Effects of epoxidation and nitration on ballistic properties of FOX-7, Z. Anorg. Allg. Chem. (ZAAC) 639 (2013), 982-987.

https://doi.org/10.1002/zaac.201300086

[30] H. Dorsett, Computational Studies of FOX-7, A New Insensitive Explosive, DSTO Aeronautical and Maritime Research Laboratory, PO Box 1500, Salisbury, South Australia, AR-011-596, September, 2000.

[31] X. Fang and W. G. McLuckie, Laser ignitibility of insensitive secondary explosive 1,1diamino-2,2-dinitroethene (FOX-7), J. Hazard. Mater. 285(21) (2015), 375-82. https://doi.org/10.1016/j.jhazmat.2014.12.006

[32] T. Zhou, Y. Li, K. Xu, J. Song and F. Zhao, The new role of 1,1-diamino-2,2dinitroethylene (FOX-7): two unexpected reactions, New J. Chem. (2017), 1. https://doi.org/10.1039/C6NJ03370A

[33] H. Gao and J. M. Shreeve, Recent progress in taming FOX-7 (1,1-diamino-2,2dinitroethene), RSC Adv. (2016), 1. https://doi.org/10.1039/C6RA12412G 
[34] J. J. P Stewart, Optimization of parameters for semiempirical methods I. Method, J. Comput. Chem. 10 (1989), 209-220. https://doi.org/10.1002/jcc.540100208

[35] J. J. P Stewart, Optimization of parameters for semi empirical methods II. Application, $J$. Comput. Chem. 10 (1989), 221-264. https://doi.org/10.1002/jcc.540100209

[36] A. R. Leach, Molecular Modeling, Essex: Longman, 1997.

[37] P. Fletcher, Practical Methods of Optimization, New York: Wiley, 1990.

[38] W. Kohn and L. Sham, Self-consistent equations including exchange and correlation effects, J. Phys. Rev. 140 (1965), 1133-1138. https://doi.org/10.1103/PhysRev.140.A1133

[39] R. G. Parr and W. Yang, Density Functional Theory of Atoms and Molecules, London: Oxford University Press, 1989.

[40] A. D. Becke, Density-functional exchange-energy approximation with correct asymptotic behavior, Phys. Rev. A 38 (1988), 3098-3100. https://doi.org/10.1103/PhysRevA.38.3098

[41] S. H. Vosko, L. Wilk and M. Nusair, Accurate spin-dependent electron liquid correlation energies for local spin density calculations: a critical analysis, Can. J. Phys. 58 (1980), 1200-1211. https://doi.org/10.1139/p80-159

[42] C. Lee, W. Yang and R. G. Parr, Development of the Colle-Salvetti correlation-energy formula into a functional of the electron density, Phys. Rev. B 37 (1988), 785-789. https://doi.org/10.1103/PhysRevB.37.785

[43] SPARTAN 06, Wavefunction Inc., Irvine CA, USA, 2006.

[44] M. J. S. Dewar, The Molecular Orbital Theory of Organic Chemistry, New York: McGraw-Hill, 1969.

[45] M. J. S. Dewar and R. C. Dougherty, The PMO Theory of Organic Chemistry, New York: Plenum-Rosetta, 1975. https://doi.org/10.1007/978-1-4613-4404-9

[46] I. S. Dmitriev, Molecules Without Chemical Bonds, Moscow: Mir Pub., 1981.

[47] L. Türker, Recent developments in the theory of explosive materials (371-404), in: Jansen JT (Ed.), Explosive Materials, New York: NOVA, 2011.

[48] R. Guirguis, D. Hsu, D. Bogan and E. Oran, A mechanism for ignition of hightemperature gaseous nitromethane-The key role of the nitro group in chemical explosives, Combust. Flame 61(1) (1985), 51-62.

https://doi.org/10.1016/0010-2180(85)90072-0 
[49] P. Politzer, M. C. Concha, M. E. Grice, J. S. Muray and P. Lane, Computational investigation of the structures and relative stabilities of amino/nitro derivatives of ethylene, J. Mol. Struct.: THEOCHEM 452 (1998), 75-83.

https://doi.org/10.1016/S0166-1280(98)00136-5

[50] E. A. Ishmaeva, V. M. Berestovitskaya, I. A. Litvinov, Y. A. Vereshchagina, E. G. Yarkova, G. R. Fattakhova, D. B. Krivolapov, S. V. Makarenko, E. V. Trukhin and I. V. Pavlova, Synthesis and structure of 1-bromo-1-nitro-2-piperidino(cyclohexylamino)-2phenylethenes, Russ. J. Gen. Chem. 71(3) (2001), 429-436.

https://doi.org/10.1023/A:1012373505297 